\title{
Most Significant Change in conflict settings: staff development through monitoring and evaluation
}

\begin{abstract}
:
Capoeira4Refugees is an NGO that uses the Afro-Brazilian art-form of Capoeira to promote psychosocial well-being in children affected by conflict and occupation. Capoeira4Refugees introduced the Most Significant Change (MSC) methodology to monitor and evaluate project implementation and impact across two locations in the Middle East. Analysis of interviews conducted with five field staff revealed that in line with, and building on previous research, MSC became an empowering tool that led to staff development. The potential for MSC to build staff reflexivity, independence and leadership has implications for other organisations working in conflict areas, particularly in situations of remote management.
\end{abstract}

In conflict-affected communities, children and youth are particularly vulnerable to marginalisation, violence and feelings of hopelessness, whilst trauma too often goes unaddressed (Ayalon 1998, Arafat and Thahabieh 2006). Neglect of these issues, or outsiderimposed approaches to addressing systemic concerns, have been referred to by some as 'ideological violence' (Dawes 2001, 297). Culturally-relevant, age-sensitive and holistic approaches to psychosocial support for conflict-affected youth is, therefore, extremely important and yet exceedingly complicated.

Capoeira4Refugees, a London-based Non-Governmental Organization (NGO), aims to provide psychosocial support for conflict-affected youth, using the Afro-Brazilian art form Capoeira as a means of strengthening social skills, cohesion and confidence levels among youth. Many of Capoeira4Refugees's field staff are themselves from the communities they support, that is, they may also be described as conflict-affected youth. Capoeira4Refugees recognizes that achieving its objectives is a highly complex process with room for continual improvement, and seeks to engage its staff in its learning process. For these reasons, in 2013 Capoeira4Refugees introduced the Most Significant Change (MSC) technique for project monitoring and evaluation (M\&E) to provide more robust qualitative evidence of its impact and to help further strengthen its programme design. After a year of MSC implementation, Capoeira4Refugees has learned a variety of programmatic lessons through MSC, but also found that MSC has itself influenced its staff members' ability to provide high-quality holistic support.

This article provides a case study of Capoeira4Refugees's use of MSC, with particular focus on how MSC has shaped both programming and staff capacity. The article begins with an overview of Capoeira4Refugees's programming and its strategic use of Capoeira, followed by an analysis of research into the use of MSC in other contexts and a description of how Capoeira4Refugees uses MSC. Subsequently, data gathered from Capoeira4Refugees's field teams is presented, along with a discussion about how their experience provides insight to the role MSC can play in psychosocial programming with conflict-affected children and youth.

\section{Capoeira4Refugees: Psychosocial support for youth through Capoeira}

Capoeira4Refugees aims to use the combination of play, dance, music and martial art that makes up Capoeira, as a means of promoting psychosocial well-being in young people. Capoeira games take place in a circle, which is headed by 'capoeiristas' playing music. One 
person leads the singing whilst everyone else responds with a chorus. Two people 'play' Capoeira together in the middle of the circle, responding to the corporal questions posed by their 'camarada' (comrade) with an array of jumps, twists, spins and kicks, always maintaining eye-contact with one another.

Capoeira is not about physical contact, nor winning or losing, as reflected in the very language used; it is a game between 'comrades' rather than a fight with an opponent. Capoeira is about teamwork, pro-social learning and cultural awareness (Capoeira 2006) and scholars have argued that through such processes it can lead to reduced aggression, empowerment and improved well-being (Assunçao 2005, 210-11).

Play, music and movement are each cornerstones of recognized therapeutic interventions, with research evidencing the positive psychosocial impacts of each discipline. For example, play therapy has been found to have positive effects on children's social adjustment, behaviour and personality, and as such is used to treat various emotional and behavioural problems (Bratton et al 2005). Music therapy has also been found to have positive psychological consequences (Gold et al 2004) and to be an effective treatment for trauma (Sutton 2002). Similarly, there is a well-established link between dance, or movement, and quality of life, subjective well-being, mood and affect (Koch, et al 2014).

In addition to its dance-like movements, Capoeira is also considered by many to be a martial art and a strenuous work-out. The impact of exercise on psychosocial well-being is well documented (i.e. Daley 2008). The link between martial arts and adolescent well-being is complex, with a wide range of factors at play in influencing the social and psychological outcomes of martial arts practice (Vertonghen and Theeboom 2010). Nonetheless, there is evidence to suggest martial arts can lead to reduced feelings of depression, anxiety and stress (Wang et al 2014) and may enable positive behavioural and emotional changes in aggressive adolescents (i.e. Twemlow et al 2008).

Capoeira4Refugees teaches groups of children and adolescents throughout the Middle East, the majority of whom are refugees or internally displaced people. All have been affected by conflict or occupation, and therefore are likely to have experienced extreme violence, trauma and loss, and taken on demanding responsibilities despite their young age. As such, it is common for students who join Capoeira4Refugees classes to act out in a variety of ways. Behaviours include aggression, hyper-activity and anxiety. Capoeira4Refugees aims to use the mixture of fun and discipline in Capoeira to provide some emotional outlet and therapeutic benefit to these youth.

Ideally, classes contain approximately 20 students of mixed gender where possible, although they are often gender segregated due to cultural expectations. Ages vary from approximately 6 to 25, with students normally attending age-specific groups. Most of the Capoeira trainers are local capoeiristas, who speak the relevant dialect and have been training Capoeira 1-10 years. Classes include movements and music as well as discussions around social issues, facilitated by a psychosocial counselor or the trainers themselves. The frequency of classes varies by location. In the first location included in this study (see below), which we will refer to as Fire city, trainers travel to different sites to give weekly classes to various groups of students. Classes take place both inside and outside registered refugee camps. Most classes are voluntary, although occasionally classes are held in schools, where students attend as part of the curriculum. In a second location, which we will refer to as River city, trainers live and 
grew up in the small community where they teach. Each group of students has access to at least three Capoeira classes a week and attendance is voluntary.

\section{History, Methodology and Theory of Most Significant Change}

Most Significant Change, or MSC, is an M\&E methodology that was introduced into humanitarian circles about a decade ago by the release of a manual (2005) by Rick Davies and Jess Dart. It is still not widespread in use, but is gaining in popularity. The guide walks development practitioners, generally non-researchers, through a qualitative process focused on storytelling, which they use to monitor progress while implementing project activities. Throughout the life of a project, staff collect 'stories of change', either from beneficiaries or through observation. Stories may range from a sentence or two in length, to several pages, and can tell of any type of change that is considered significant by the teller. Stories may then be allocated into domains of change, that is, themes about types of change. Then, staff, community leaders, or other stakeholders, discuss a set of stories collected in one location in a given time period, and agree - by consensus - on one or a few stories that are most significant. They then pass their selected story or stories, and their rationale, up the management ladder; management may repeat the process with stories from multiple project sites. An additional thematic analysis of the story data may also be conducted.

The goal of MSC is not to develop a representative dataset documenting project activities. Rather, it is to consider how project beneficiaries and staff conceptualize change, as well as to identify what changes are happening where the project is happening and how this relates or not - to the original project objectives. MSC is specifically designed to allow for documenting not just the intended changes, but also unintended changes. Wilder and Walpole (2008, 530-531) describe MSC as a way of systematically recording qualitative evidence about a project, by engaging participation from a wide range of project stakeholders. Furthermore, 'MSC stories provide information on a wider suite of changes such as changes in attitudes, behaviour, well-being and livelihoods of the intended beneficiaries, and in a format that is easily accessible' (Wilder and Walpole 2008, 534).

MSC has been found to be an effective complement to other M\&E methodologies. An increasing body of research documents lessons-learned from use of MSC (Willetts and Crawford 2007, Hall 2014, Wilder and Walpole 2008, Wrigley 2006, Choy and Lidstone 2013, Kloosterman et al 2012). This paper is intended to add to that body of knowledge, with specific focus on MSC's usefulness for influencing staff and project development.

Previous research has explored how MSC can strengthen project implementation and build the skills of staff or community members. For example, the abilities needed for MSC are somewhat unique to MSC, in comparison with other M\&E techniques, but overlap with other skills that implementing staff often seek to develop. 'The evaluator's task in MSC... is likely to require competencies in narrative writing, facilitation of groups, and interpreting ambiguous events' (Hall 2014, 316). By engaging in MSC, staffs' professional capacities are therefore strengthened.

Various practitioners have suggested that staff who write and select stories grow more attentive to the people they serve, to achieving their objectives and to impact. In a study of the use of MSC in Laos, 'the very process of debating the significance of stories of change fostered an organizational culture of reflection. Staff reported feeling a greater focus on the broad purpose of their work' (Willetts and Crawford 2007, 375). In an educational leadership course with Pacific Islanders, Choy and Lidstone $(2013,219)$ found that the MSC process 
required 'participants to reflect critically and analyze the outcomes and changes they have experienced or observed throughout their participation... traditional evaluation tools do not allow this level of in-depth criticality.'

This reflection in some cases led to greater initiative in everyday project implementation. For example, in an environmental project in Cambodia, Wilder and Walpole found $(2008,534)$ increased confidence and capacity among their field staff, connected to an 'improved awareness and understanding of the outcomes and impacts of their work. The field teams now analyse situations and issues and decide how to respond to them without constant guidance from Team Leaders, working together better as a team'. Willetts and Crawford (2007, 370) observed that, while it was not clear from their evaluation how project beneficiaries themselves were affected, project staff were more sensitive to beneficiaries' point of view and then more proactive in developing relationships with them, which may lead to better project outcomes.

MSC helps field staff to engage with both their own values and those held by organizational decision-makers. One of the hallmarks of MSC is the selection process, which entails a discussion about which story is most significant. According to the MSC guide, selection is about making sense of a large volume of information and then choosing and documenting criteria by which the "most significant" change story is chosen. 'The selection of the most significant stories is inherently an expression of the values of the people on the selection panel' (Wrigley 2006, 5). When selection results are transparent and discussions documented, those values are also documented. In fact, '[Dart and Davies] go so far as to argue that the deliberation and dialogue surrounding the selection of stories is the most important part of the MSC technique' (Hall 2014, 317).

Unlike other evaluation mechanisms, MSC is specifically designed to identify and verbalize values, potentially provoking intra-team conflict. Dart and Davies found, when first applying MSC, that values became more visible within an organization's culture, fostering a space for discussing values within a team (2003, 150; see also Kloosterman et al 2012). Choy and Lidstone similarly reported $(2013,224)$ that MSC revealed 'cultural norms of the client group and in this case clearly identified the values that prevail in the cultural, workplace and community context of the participants.'

As staff pay more attention, strengthen their programming skills and engage in discussion about values, strategic planning is often affected. In fact, Wilder and Walpole found (2008, 534) that 'many stories are not about changes arising from the project but of issues that required a reaction from the field team. These stories receive the most attention during the meetings... At the end of each meeting a simple list of actions is made, with clear responsibilities, and checked at the following meeting.' Similarly, Willetts and Crawford concluded $(2007,375)$ that the most notable utility of MSC for their programme was for midproject adjustments, informing future project design, and helping each stakeholder develop their knowledge base. In their early usage of MSC, Dart and Davies $(2003,149)$ found that programme staff used stories and interpretations in planning new activities, and that the most useful stories were those which expressed lessons learned. They also, however, observed that some respondents felt MSC did not provide a clear enough system for responding to lessons learned.

Many researchers expressed surprise at these programmatic effects of MSC, but it was in fact Dart and Davies' original intention that MSC be a means by which effectiveness be 
continually strengthened. In an article introducing MSC to the non-profit evaluation community $(2003,140)$, they wrote, 'MSC can be conceived as a form of dynamic values inquiry whereby designated groups of stakeholders continuously search for significant program outcomes and then deliberate on the value of these outcomes. This process contributes to both program improvement and judgment.' Part of their rationale behind using stories as the medium for data collection was that 'they encourage non-evaluation experts to participate, they are likely to be remembered as a complex whole, they can help keep dialogue based on concrete outcomes rather than abstract indicators... [and they] can infiltrate the collective memory of an organization, helping program staff to gain and retain a more deeply shared understanding of what is being achieved' $(2003,140)$. While other forms of $\mathrm{M} \& \mathrm{E}$ may be integrated into project design, MSC is explicitly intended to interplay closely between planning, monitoring and implementing.

\section{Why and How Capoeira4Refugees Uses Most Significant Change}

MSC was introduced into Capoeira4Refugees' projects in September 2013, out of a desire to capture qualitative data that would reflect the depth and diversity of its programmes' intended and unintended impacts, and in doing so shape future programming. Initially, staff were asked to write stories based either on their own observations or on stories told to them by students; because many of Capoeira4Refugees' beneficiaries are young children, it would not be feasible to ask them to write stories until staff themselves were highly comfortable with the methodology.

There have been variations in MSC implementation due to the specific design and location of each project. The first team to adopt MSC was that in River City, where the Capoeira programme is remotely managed by a team leader based in another country. The team received an orientation to MSC by their manager but initially found the idea confusing. With further guidance and with the introduction of an MSC guide written specifically for Capoeira4Refugees staff, the team did soon take to the idea (November, 2013). At first, they produced stories sporadically, but after a few months were encouraged to provide one story per person every two months. Once this became habit (February 2014), staff were asked to meet to discuss the stories, choosing one story, which they agreed to be the most significant. Staff were asked to record as much of this discussion as possible and to relay to their manager the final reason for their choice of story. While the roll-out of MSC in River City has been mostly smooth, there have been challenges to documenting both stories and the selection process, and to communicating decisions to the manager, due to limited access to phones, computers and internet.

The team in Fire City were trained by Hannah, one of the authors, who also oversaw the implementation of the technique. This team found story collection more difficult than the team in River City, and in addition, the project itself faced many difficulties. Furthermore, staff often felt that there were no significant changes to write about, the role of M\&E was evolving, and there was a high level of staff turnover. As a result, MSC implementation was frequently disrupted. There was a period of monthly story collection and discussion towards the end of 2013, followed by a hiatus of approximately six months; since May 2014, most trainers have once again been producing monthly stories. There are many differences between the experiences in the two cities, but it is beyond the scope of this article to speculate as to why MSC has been implemented more effectively in River City than in Fire City.

\section{Research methodology}


This paper is based on an on-going process of documenting lessons learned and staff reflection during Capoeira4Refugees' roll-out of MSC during its first year. Building on themes identified through the reflection process, interviews were conducted by international staff with field staff in June-August 2014 to understand how the lessons learned were being experienced at all levels of the organization and to gain further insight into the role of MSC in Capoeira4Refugees' programming.

The authors understood that, so far, most widespread use of MSC has been in multi-year development programming in relatively stable countries, rather than in refugee and conflict settings such as where Capoeira4Refugees operates. Therefore, starting in October 2013, we began bi-monthly reflection discussions to process issues that arose, identify adaptations to the methodologies, and document lessons learned.

Nearing the end of the first year of implementation, we found that our discussions increasingly referred back to the use of stories in empowering local staff, as well as identifying programmatic issues. A subsequent analysis of notes taken during the months of discussions led to the identification of key themes, which were used to develop an interview schedule for field staff.

Four interviews were conducted with staff operating in River City, in Arabic then transcribed to English. Kathryn listened to the Arabic recordings and took notes, while Hannah did a manual thematic analysis of the transcripts. A fifth interview took place in Fire City; it was recorded and transcribed in English, and both authors based our analysis on the transcription. Hannah has worked closely with the interviewee, Majd (all staff names anonymized), and the data from this interview reflect an ongoing relational dynamic which is different from that expressed by staff in River City, who rarely see their international colleagues. Interviews ranged from 20 minutes to one hour in length.

This research reflects learning after one year of MSC implementation, with varying degrees of success in different contexts, and we acknowledge that further research is warranted to identify further uses of MSC and develop its use within Capoeira4Refugees' programme.

Findings and Discussion: Three Stages of Programme and Staff Development Through reflection and interviews, three themes were identified that demonstrate how staff have used MSC to strengthen their ownership of, and capacity to implement, Capoeira4Refugees programming. The themes can be viewed as stages that follow a progression whereby staff have become increasingly proactive in their roles as they grew in their confidence with MSC.

Stage 1: Project team members become more observant and reflexive.

Previous research has reported that, like other qualitative evaluation methodologies, MSC can facilitate a process of self-reflection and in doing so, enhance staff capacity to conceptualize project impact (Wilder \& Walpole 2008; Wrigley 2006). Capoeira4Refugees staff echoed this view, talking about how through writing stories, they became more aware of the changes in the children.

"The stories help us a lot to spot the changes occurring inside the children's mind from one story to the other" - Manar, River, Female. 
As a part of this improved ability to conceptualize project impact, staff also reported becoming more observant and attentive to needs and changes in their students.

"We could see that a child had changed, but then when we write about them, we take more interest and can see more clearly what their particular problems are... We take a closer interest in them than before" - Aseel.

"Simply because we have to write these stories, we have to focus more on the children. We have to take notice of the child from the moment he enters the project to see how he changes afterwards." - Fareed, River, Male.

Noticing these changes, and documenting them in the form of stories, then led to feelings of pride and accomplishment, a sense of having done something meaningful, including production of a story which communicates this success to a wider audience.

"First of all, if I write a story and feel like it's well-written, it makes me happy. I'm happy because I'm helping children... and having an influence" - Ahmed, River, Male.

"When I write a story about a child that benefitted from the project, in the end I feel productive within society, that I benefitted society in some way." - Fareed.

Stories help create shared understandings within an organization, and storytelling can be an effective tool for bringing about community change through a shared experience. In MSC, this happens during informal chats amongst the team as well as selection discussions. This simple methodology for discussion and reflection was easily communicated to the team who rapidly learned to participate and began their own reflective activities. Staff reflected on, and benefited from, others' stories, as well as the ones that they themselves identified and wrote. For example, Majd, reported feeling proud particularly after hearing the stories of others.

"When I read other stories, it affects me because sometimes you don't see what they saw when they wrote these stories. So you feel so happy and proud cos you know those kids and you hadn't seen this change or this story" - Majd, Fire, Male.

This self-reflection has been particularly valuable in River City, where staff are working in extremely difficult circumstances, with high security concerns. Creating and communicating accounts of experiences in such a context is often a helpful means of processing experiences and dealing with stress (Bassett 2012).

Stories also highlighted obstacles to the team's ability to impact the lives of the children with whom they work. Staff willingness, or reluctance, to tell stories in Fire City was likely influenced by their own level of confidence that they were indeed having an impact: that which is not told is as important as that which is told. Where staff found it hard to write stories, there was either an issue with the project, for example that they felt there was no significant change to tell, or a barrier in communication between staff and beneficiaries whereby change was happening but staff were unable to gather this information.

"I hate like when I have to write a story if I didn't [see] anything..., like you talk to [the beneficiaries], like why you didn't come, why you stopped participate? Their answer always like "I don't know, I don't know, I don't know". Like I cannot get something from them to write a story..." - Majd 
Staff in River City did not express similar frustrations, and in fact regularly visited students in their homes to understand their situation better and add detail to their stories. When staff members are telling stories, they are reflecting on, noticing and taking pride in their work; when staff have resisted telling stories, Capoeira4Refugees has now begun to engage in strategic discussions to identify why staff are not noticing change or are experiencing frustration.

Stage 2: Staff become more actively critical and analytical, developing useful cognitive skills. In order to write successful stories, those implementing MSC must learn to be selective. They must choose which child to write a story about, which entails understanding and identifying meaningful change, and they must then choose what information to include within their story. In MSC, there are no 'right choices'; the important part is understanding why a particular choice has been made. For this reason, staff were required to explain why they felt their chosen story to be the most significant. One trainer in River City explained that she has learned to think very selectively when synthesizing a large amount of experiences into a concise story.

"So from the beginning I start a story with all its details, even if I'm trying to keep it short. That's the problem, that I always have to go back and condense it. Ahmed's like, 'Aseel, summarize. ...' So I write about two pages, sometimes three, and then I try to summarize it... [Then] when I write a story I write five lines at the end about why I chose that particular child." - Aseel.

For these reasons, Willets and Crawford (2007) suggest that MSC requires greater development of higher-order skills than many conventional M\&E methods, benefits of which can be felt across the project as a whole. Indeed, as mentioned above, Wilder \& Walpole (2008) found that field teams became better able to analyse situations and decide how to respond to them without constant guidance from Team Leaders.

In the current project, such benefits were most notable in River City. The manager, who is based in a neighbouring country, commented that over the course of the year using MSC, her staff became more critical and analytic, which helped her to more effectively lead her team from a distance. For example, when she debriefed her staff, they were more selective about what to prioritize in a short meeting than they had been even six months ago.

Inevitably, through this process of selection, all stories end up being influenced by the eyes, interpretations and values of their authors (Diamond 2005). Staff are becoming more aware of these influences on how stories are told.

"Some instances you don't want to write about, and other instances we don't, I mean... Reality is always different from the story. You can't think you're going to put the whole reality into a story. It will always be different, for sure" - Fareed

Willets and Crawford (2007) also drew attention to the way that the 'taken-as-given assumptions of the teller and writer of a story can influence story form. Although this process has drawbacks as the writer 'may well omit details that are in fact pertinent to a different readership' (p. 372), a positive by-product is that staff may better reflect on their own values and beliefs. Indeed, this was found to be the case in River City, where staff are asked to explain why they chose one story as the most significant during the reporting period. At first, 
explanations were simple, that they chose one story because that person had changed the most or the change was the most obvious. However, over time, explanations demonstrate more reflection and consideration of values. For example, a more recent explanation for story selection was that the chosen story 'best reflects the circumstances in which they are working, in which the kids live, and how Capoeira can provide an alternative to extremist thinking and kids joining extremist groups' (taken from project report).

The team in River City is meeting together regularly and has developed a close working relationship. The interviewees from River City each referred to conversations they have with their team-mates about both the stories and the children described in the stories. This collaboration has helped them to develop critically as a team.

As explored above, previous research has found that the MSC process often helps staff to develop a deeper understanding of organizational values. This improved understanding was particularly important for River City staff, considering the limited opportunities that they have to interact with other members of the NGO and to discuss the organization's ethos.

"When I started working, I didn't really understand what the work was about, I didn't really get the situation. What Capoeira4Refugees is, what its goals are... but then when I started to write the stories and make a bit of effort, I started to get the point... It's a humanitarian goal... [teaching] movements and music, and human things, like respect, freedom, dedication" - Fareed.

Interestingly, in Fire city, where staff have found it difficult to write stories and consequently had few story discussions, Majd found it more difficult to articulate his values. When asked specifically about his values, he instead reverted to speaking about the behaviour change already captured in a story.

"I feel the values as like I explain the story that he have been changed from his behaviour in the class. He was a bit spoiled, had a lot of energy, he wanted to show off. Now he is more respecting the other kids... he is willing to listen, to talk to them."- Majd

Despite his resistance, or inability, to identify and reflect on his values per se, Majd did write an interesting story which led to a discussion amongst the team in Fire City around a particular value predominant amongst the beneficiary community. The ensuing discussion helped international staff to better engage in building a shared understanding of cultural values with field staff.

Even where staff are not yet able to articulate their own values, the MSC process can still lead to greater shared understandings of others' perspectives and values; something particularly important in the NGO context where people from different cultures work together. Indeed, the use of narratives can be a powerful means of reflecting back to a group their varied experiences and perceptions, and bringing to the fore competing explanations (Diamond 2005).

Stage 3: Staff take action: planning in response to their learning, developing systems and strategizing

Though there was no evidence in this study that Fire City staff have reached this stage, field workers in River City began to demonstrate an even greater confidence and capacity for project management. Using MSC as a foundation, they have devised a range of systems to 
ensure the effective gathering of information on a timely basis. For example, they described how as they gained experience writing stories, they started to plan and carry out psychosocial assessments of each child.

"We weren't writing stories and, for example, a new child would come, and before we'd be like, "Oh, here's a new kid, OK, come and play. OK, now go home. Whatever." Now when a new child comes...[someone on the team] stops, observes the new child... I write this stuff down... A week or two later - this is all while we're still giving training - we do another assessment of this new child... We find out if there has been any improvement, or the reverse, and on this basis we approach the work" - Ahmed.

Next, the staff in River City explain how the story writing process has brought about the development of personal records on each child.

"So now there are a number of stories, kept at home, this is before [our manager] asks for them, and each child has a story with a record of his progress. This has really helped us. Now if you want to make a stew, you've got the ingredients and you just need to prepare it" Ahmed.

Through the MSC process, staff became accustomed to writing, which led to confidence in other management and planning tasks, including the introduction of lesson planning.

"Yeah, in the beginning Capoeira was an entertainment, and then I came to realize I'd found a real job, not just a game... I started to prepare for the sessions I would take, and evaluate the sessions, how the children perform, which children engaged the most, which children I need to push more." - Aseel.

Research has found that the MSC process can lead to better team-work (Wilder \& Walpole 2008). Indeed in the current study, staff in River City described how the need to gather information for stories prompted both team discussions and team visits to students' houses.

Unlike Wilder and Walpole's experience in Cambodia, River City staff did not describe these changes to their activities as addressing issues that emerged, or making an action plan for adapting the project design, rather as a cooperative effort to be more proactive and creative in their endeavour to provide the best possible support to their students. This team development, with a clear assessment and planning component, may be described as a key to success of Capoeira4Refugees' remotely-managed programme in River City.

\section{Conclusion}

Capoeira4Refugees's field staff have, for the most part, enjoyed the MSC process, and MSC has been a means by which their capacity has developed. MSC has facilitated empowerment and programme ownership, characterised by attentiveness to the needs of students, and a committed and focussed attempt to meet these needs. Capoeira4Refugees's staff are young with little experience in humanitarian or psycho-social interventions, and many are themselves victims of the conflict in their country. Through using MSC, they have developed skills in observation and reflection. Over time, their critical thinking and analytical skills have been strengthened. Finally, some staff have become increasingly proactive, innovative, and responsive to their students' individual and social needs. 
The River City team has learned to use Capoeira as not just a social activity, but as a tool for psychosocial support, meeting a felt need for a kind of assistance that, elsewhere, one might expect a professional counsellor to provide but which in a Middle Eastern city like River is generally unavailable and seen as socially taboo. There is some risk entailed in young untrained staff engaging in psychosocial assistance, but in a context where there are few other options, MSC has enabled them to do so reflexively and analytically.

In Fire City, Majd is the only field staff member who has been working with the Capoeira students long enough to reflect on the process over time. While other, newer, staff, have expressed that they enjoy writing stories, Majd has also identified some potential frustrations in using MSC to strengthen psychosocial programming. While Majd, like the River City staff, found that stories promoted reflection and observation, he did not demonstrate an understanding of why a field staff member, hired to teach Capoeira, should want to be reflective.

MSC promotes discussion of values, but not all staff easily engage with this concept. Efforts to engage staff in these discussions raised questions about power dynamics in an office with both international staff representing the organization's founding principles, and national field staff who hail from the affected community. If MSC effectively promotes discussion of values, we had anticipated that it would provide an equal voice to both, indeed to all, parties. However, MSC discussions developed with greater ease in River City, where international staff were largely absent, than in Fire City, where management was close by. This suggests that rather than ensuring an equal voice throughout the project teams, perhaps MSC instead served to highlight areas of perceived power imbalance.

In both locations, MSC has been used by Capoeira4Refugees to better understand the qualitative impact of its programming and identify strategic changes for project improvements. Therefore, although MSC fulfilled its intended monitoring and evaluation role, the focus of this article has been on the way in which MSC led to additional staff development and through this, improved project quality. Further research is needed into the role of MSC for challenging or affirming power structures within an NGO, and into the effectiveness of strategic adaptations that have been made as a result of MSC. Furthermore, this research has suggested that, with appropriate monitoring tools in place, remote management of projects in conflict-affected areas may in fact have some benefits over direct supervision, a hypothesis which merits further exploration.

\section{References}

Assunçao, M. 2005. Capoeira: a history of an Afro-Brazilian martial art. London: Routledge.

Ayalon, O. 1998. "Community Healing for children traumatized by war." International Review of Pschiatry 10: 224-233.

Basset, D. 2012 "I Need These Stories to Remind Me That There is Hope: Poetic Representations of Living in Israel During the Al Aqsa Intifada." Qualitative Inquiry 18 (5): 432-437. 
Bratton, S., D. Ray, T. Rhine, and L. Jones. 2005. "The Efficacy of Play Therapy With Children: A Meta-Analytic Review of Treatment Outcomes." Professional Psychology: Research and Practice 36 (4): 376-390.

Capoeira, N. 2006. A street-smart song: Capoeira philosophy and inner life. Berkeley, CA: North Atlantic.

Choy, S. and J. Lidstone. 2013. "Evaluating leadership development using the Most Significant Change technique." Studies in Educational Evaluation 39: 218-224.

Daley, A. 2008. "Exercise and Depression: A Review of Reviews." Journal of Clinical Psychology in Medical Settings 15 (2): 140-147.

Dart, J. and R. Davies. 2003. “A Dialogical, Story-Based Evaluation Tool: The Most Significant Change Technique.” American Journal of Evaluation 24 (2): 137-155.

Dart, J. and R. Davies. 2005. “The 'Most Significant Change' (MSC) Technique: A Guide to Its Use."

Dawes, A. 2001. "Psychologies for Liberation: Views from Elsewhere." Peace, Conflict and Violence: Peace Psychology for the $21^{\text {st }}$ Century. New Jersey: Prentice Hall.

Diamond, J. 2005. "Reflecting on the processes of a local evaluation." International Journal of Public Sector Management 18 (2): 178-189.

Gold, C., M. Voracek and T. Wigram. 2004. "Effects of music therapy for children and adolesents with psychopathology: a meta-analysis." Journal of Child Psychology and psychiatry 45 (6): 1054-1063.

Hall, M. 2014. "Evaluation Logistics in the Third Sector." Voluntas 25: 307-336.

Koch, S., T. Kunz, S. Lykou, and R. Cruz. 2014. "Effects of dance movement therapy and dance on health-related psychological outcomes: A meta-analysis." The Arts in Psychotherapy 41 (1): 46-64.

Kloosterman, J., E. Benning and R. Fyles. 2012. “'Measuring the unmeasurable': gender mainstreaming and cultural change." Gender and Development 20 (3): 531-545.

Sutton, J. 2002. Music, music therapy and trauma: International perspectives. London: Jessica Kingsley Publications.

Twemlow, S., F. Sacco, and P. Fonagy. 2008. "Embodying the mind: Movement as a container for destructive aggression." American Journal of Psychotherapy 62 (1): 1-33.

Vertonghen, J. and M. Theeboom. 2010. "The social-psychological outcomes of martial arts practise among youth: A review." Journal of Sports Science and Medicine 9: 528-537.

Wang, F., E. Lee, T. Wu, H. Benson, G. Fricchione, W. Wang, A. Yeung. 2014. "The Effects of Tai Chi on Depression, Anxiety, and Psychological Well-Being: A Systematic Review and Meta-Analysis.” International journal of behavioural medicine 21 (4): 605-617. 
Wilder, L. and M. Walpole. 2008. "Measuring social impacts in conservation: experience of using the Most Significant Change method." Fauna and Flora International, Oryx, 42 (4): 529-538.

Willetts, J. and P. Crawford. 2007. "The most significant lessons about the Most Significant Change technique." Development in Practice 17 (3): 367-379.

Wrigley, R. 2006. "Learning from Capacity Building Practice: Adapting the 'Most Significant Change' (MSC) Approach to Evaluate Capacity Building Provision by CABUNGO in Malawi." INTRAC Praxis Paper No. 12. 